\title{
Modelling the Maternal Oral Health Knowledge, Age Group, Social- Economic Status, and Oral Health-Related Quality of Life in Stunting Children
}

\author{
Ratna Indriyanti, Three Rejeki Nainggolan, Anten Sri Sundari, Eka Chemiawan, \\ Meirina Gartika and Arlette Suzy Setiawan
}

\author{
Department of Pediatric Dentistry, Faculty of Dentistry, Universitas Padjadjaran Jl. Sekeloa Selatan 1 \\ Bandung, 40132, Indonesia
}

\begin{abstract}
The main themes are two main health problems affecting children under five in Indonesia, namely nutrition and oral health. Lack of nutrition in children can also affect their general health, and so does their oral health, leading to their quality of life. The study aimed to analyse the relationship between maternal oral health knowledge, maternal age group, social-economic status with the oral health-related of life in stunting children. This type of analytical research used a survey method on 86 mothers aged 2-5 years in one of 15 villages designated by the mayor of Bandung as a stunting locus. Maternal oral health knowledge, social-economic status, and oral health-related quality of life were assessed using a set of questionnaires that have been pre-tested to non-participant mothers. The hypotheses of the conceptual model were tested using structural equation modelling-partial least squares. The results showed that $16.7 \%$ of the variance in OHRQoL was explained by maternal oral health knowledge and the maternal age group. Social-economic status has an indirect relationship to OHRQoL by predicting the maternal oral health knowledge $10.6 \%$. The path coefficient between maternal age group and OHRQoL was the strongest $(\beta=-0.350, P=0.000)$, followed by SES and maternal oral health knowledge $(\beta=0.325, P=0.04)$ and to OHRQoL $(b=0.215, P=0.02)$. The overall predictive power of the model was $10.6 \%$. This result indicated maternal oral health knowledge, social-economic status, and maternal age group related to children's oral health quality of life.
\end{abstract}

Keywords: Oral health knowledge, oral health-related quality of life, stunting, social-economy status.

\section{INTRODUCTION}

Indonesia faces nutritional problems that may have a severe impact on the quality of human resources in the future, one of the nutritional problems currently a significant concern is stunting in children under five. As one of the targets of the Sustainable Development Goals, stunting has become the focus of the government's attention to create a program that targets reducing the stunting rate to $14 \%$ by 2024 [1]. Indonesia's current position is third in the world in terms of stunting prevalence, which is $27.7 \%$, but it is still above the WHO standard, $20 \%$ [2].

Stunting can occur due to three main factors described by the UNICEF Framework; unbalanced food intake, low birth weight, and a history of the disease. Diseases that usually last a long time include oral disease or dental caries [3]. Availability of proper nutrition is essential for the growth, development, maintenance, and repair of healthy teeth and oral tissues. Stunting growth was found to have a significant correlation with various dental health problems. The number of primary dental caries was high in underweight and stunted children [4,5]. Apart from the

*Address correspondence to this author at the Department of Pediatric Dentistry, Faculty of Dentistry, Universitas Padjadjaran JI. Sekeloa Selatan 1 Bandung, 40132, Indonesia; E-mail: arlette.puspa@fkg.unpad.ac.id problem of stunting, in 2015, Indonesia, through its Ministry of Health, issued a target for children aged 12 years to be free of caries by 2030. If the problems of stunting and caries can be studied simultaneously, we can work on alleviating two problems at once.

Oral diseases are known to negatively impact physical, functional, and emotional wellbeing and thus adversely affect the quality of life of stunted children. Tooth decay and oral disease in children can cause difficulty socializing, chewing, swallowing, speaking, sleeping, lack of appetite, low self-esteem. and behavioral changes that can impair school performance. The current concept of dental and oral health does not only look at the status of dental caries but must involve functional, psychological, social aspects and the experience of pain or discomfort. Therefore, oral Health-Related Quality of Life (OHRQoL) has become the ultimate goal of good oral care [6].

Maintaining the health of preschool children to avoid dental health and nutrition problems is still the joint responsibility of parents. However, because the mother is the closest person to the child, the mother's educational background, occupation, knowledge, and perception are the benchmarks for the child's condition. In addition, family economic status supports the variable mentioned earlier. The government released a regulation regarding the determination of the village's 
location for stunting reduction and prevention programs in the city of Bandung. There are 15 villages from 13 districts with a moderate to very high prevalence of stunting, one of which is the Sukawarna in the Sukajadi district. This research will be conducted in Sukajadi District on mothers who have stunted children aged two to five years old based on the Sukajadi Health Center data. Research conducted by Agustian et al. stated that the prevalence of stunting in Sukajadi Public Health Center was $40.3 \%$ [7]. In this context, we hypothesized that mothers' social-economic status and oral health knowledge might affect their perception of subjective oral health outcomes of their stunting children. Moreover, such perception might be moderated by the influence of the maternal age group. Thus, this study aimed to analyze the relationship between maternal oral health knowledge, social-economic status, maternal age group, and oral health outcome (OHRQoL).

\section{METHODS}

Ethical approval was obtained from the Health Ethics Committee of Universitas Padjadjaran, Bandung, Indonesia (ID: 676/un6.KEP/EC/2020). In this cross-sectional and relational study, the population of 110 mothers who have stunting children aged 2-5 years has been recorded in the database at the Sukajadi Health Centers, Bandung, Indonesia. The sample was calculated with the Slovin formula (confidence level 95\%, the margin of error 5\%) determined by the random sampling method and yield to the size of a minimum of 86 mothers. The participants were informed about the study, and written informed consent was obtained.

\section{Conceptual Model}

The conceptualized model was modified and adapted as follows; first, a detailed literature search was conducted to find published literature regarding OHRQoL in children. Second, a systematic search of the published literature was performed on the following databases: PubMed, ISI Web of Knowledge, and Google scholar. Search terms included oral healthrelated quality of life, OHRQoL, and quality of life in stunting children. Finally, a conceptual model was prepared based on the data obtained from the literature [8-10] and the previous models of OHRQoL [11]. The components and scoring of the endogenous and exogenous variables of the conceptual model are as follows (Figure 1).

\section{Survey Instruments}

Endogenous variables are ECOHIS and $\mathrm{P}-\mathrm{CPQ}$; increasing total scores indicate decreasing OHRQoL. Exogenous variables are family socioeconomic status, maternal knowledge. Maternal age act as moderating variable. Maternal age group and classified into Indonesian Health Ministry aged group and coded into $1=$ late adolescence 17-25 years old; $2=$ =early adulthood 26-35 years old; $3=$ late adulthood $36-45$ years old; $4=$ early elderly $46-55$ years old [12].

The instrument used is a structured close-ended questionnaire that has previously been tested for validity and reliability. The questionnaires addressed socio-demographic characteristics, oral health-related knowledge, social-economic status, and OHRQoL. Maternal oral health-related knowledge questionnaire

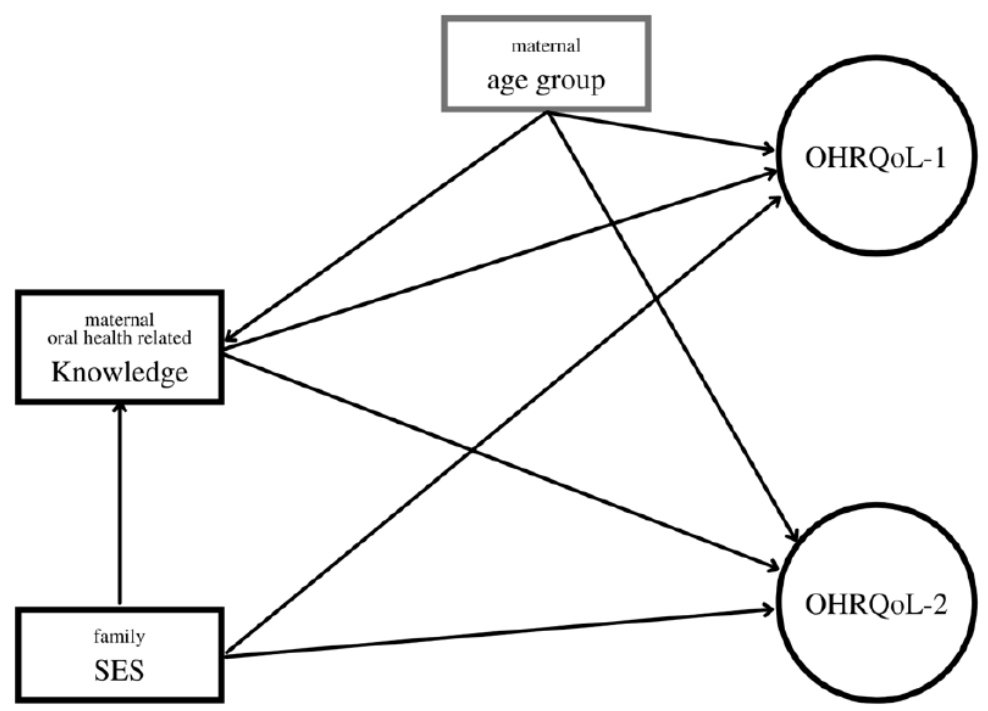

Figure 1: Conceptual framework of study variables, adapted from revised Wilson and Cleary model [11]. 
(OHK-Q)was trans adapted from the World Health Organization into Bahasa Indonesia by Ghufroni et al. [13]. The questionnaire consists of 12 items classified into three indicators; knowledge about tooth brushing practice, dentist visit, and oral health care other than tooth brushing. Example "when is the ideal minimum time for children to start regular dental check-ups?". Response options were multiple choice answers and scored 0 for the wrong answer and 1 for the correct answer. The collected data will be assessed and calculated using a formula-the final scores or oral health-related knowledge range from 0 to 12 . Higher scores indicated better oral health knowledge. Confirmatory factor analysis (CFA) was used to confirm the validity of the questionnaire.

Socioeconomic status (SES) is the social standing or class of an individual or group. It is often measured as a combination of education, income, and occupation as indicators. In this study, we developed a questionnaire based on three indicators and adapted it to the conditions of the people in the city of Bandung. Twelve closed-ended items with five response options $1-5$. The total score of the SESQ ranges from 0 to 60 , where a higher result indicates a better status.

The OHRQoL questionnaire was assessed using Parental Caregiver Perception Questionnaire 16 (PCPQ 16) and Early Childhood Oral Health Impact Scale (ECOHIS). The P-CPQ questionnaire includes 16 items related to four areas (oral symptoms, functional limitations, emotional wellbeing, social wellbeing), to which possible answers the following score was assigned: $0=$ never; $1=$ almost never; $2=$ occasionally; $3=$ often; 4=very often. The total score of the P-CPQ questionnaire ranges from 0 to 64 , where a higher result indicates a worse quality of life.

The ECOHIS questionnaire was developed and validated in the USA to measure the impact of oral health on children under five years old from a family standpoint [9]. It includes 13 questions divided into two domains; 9 questions about the impact of oral health on the children and four questions about the impact on the family. Responses are coded to $0=$ never; $1=$ often; $2=1$ do not know. The total score ranges from 0 to 26 , where a higher result indicates a worse quality of life.

\section{Pre-Testing Instrument}

For reliability analysis, the questionnaires were filled out in this study by 30 mothers who were not included in the study sample. In terms of test-retest reliability, the questionnaires were filled twice ten days apart. The comprehensive questionnaire (ICC) ranged between 0.57 and 0.93. The internal consistency of the questionnaire was also evaluated by reliability coefficients (Cronbach's $\alpha$ ), which were SESQ (0.750), P-CPQ (0.843), ECOHIS (0.870), OHK-Q (0.888).

\section{Statistical Analysis}

IBM $\circledast$ SPSS $®$ Statistics 23.0 and Smart $^{\mathrm{TM}}$ PLS 3.2.9 were used for data analysis. Mean \pm standard deviation or frequency and percentage were used to describe the demographic information of the participants. In addition, we used the skewnesskurtosis test to check the normality of the study variables. As a result, the sample data showed a normal distribution, where the absolute value of skewness was $<3$, and the absolute value of kurtosis was $<8$ [14].

Spearman's correlation was used to evaluate correlations between latent variables. All differences were assessed using two-tailed tests, and the significance level was set at $p<0.05$. A structural equation model was constructed to determine the relationship between social, economic status, maternal oral health knowledge, and OHRQoL. In this study, we also included age group items to see their role in the model formed-the model's explanatory power assessed employing $R^{2}$ of the dependent outcomes. The Blindfolding procedure was used to test out-ofsample predictive power $\left(Q^{2}\right)$. The bootstrap method [15] was used to test the significance of the mediating effect of related variables in the ideal model. All statistical tests were assessed at a 0.05 level of significance.

\section{RESULT}

\section{Participant's Characteristics}

Table 1 shows the characteristics of stunting children at the Sukajadi Health Centres. Based on the inclusion and exclusion criteria, the research subjects were 86 mothers with stunted children aged 2-5 years. The majority of mothers are in early adulthood (58.1\%) and have a secondary education level $(62.8 \%)$.

\section{The Study Variables and their Correlations}

Descriptive statistics of the variables with the $\alpha$ coefficients are presented in Table 2 . In addition, a preliminary assessment of the correlation matrix between the main study variables was made using Spearman's correlation (Table 3). The bivariate 
Table 1: Characteristics of Participants

\begin{tabular}{|c|c|c|}
\hline Characteristics & $\mathbf{n}$ & (\%) \\
\hline \hline Maternal age group & & 19.8 \\
Late adolescence & 17 & 58.1 \\
Early adult & 50 & 20.9 \\
Late adult & 18 & 1.2 \\
Early elderly & 1 & 19.8 \\
\hline Maternal education level & & 62.8 \\
Lower & 17 & 17.4 \\
\hline Secondary & 54 & 50 \\
Upper & 15 & 23.3 \\
Poor & 43 & 26.7 \\
\hline Fair & 20 & 23 \\
\hline
\end{tabular}

Table 2: $\quad \alpha$-Coefficient, Score Range, Mean, and Median of Study Variables

\begin{tabular}{|c|c|c|c|c|c|}
\hline & $\alpha-C o e f f i c i e n t$ & Min-Max & Mean (SD) & 95\% CI & Median (IQR) \\
\hline \hline ECOHIS & 0.883 & $0-13$ & $6.2(3.9)$ & $5.3-7.0$ & $6.5(8)$ \\
\hline P-CPQ & 0.916 & $0-32$ & $8.3(7.0)$ & $25-9.8$ & $24.0(12)$ \\
\hline SES-Q & 0.751 & $17-32$ & $6.1-26.2$ & $24(5.5)$ \\
\hline OHK-Q & 0.907 & $0-12$ & $6.3(4.2)$ & $5.4-7.2$ & $6.5(7.3)$ \\
\hline
\end{tabular}

Table 3: Correlation Matrix of Study Variables

\begin{tabular}{|c|c|c|c|c|}
\hline Variables & $\mathbf{1}$ & $\mathbf{2}$ & $\mathbf{3}$ & \\
\hline \hline Oral health knowledge & 1.000 & & \\
\hline OHRQoL-1 (ECOHIS) & $.195^{*}$ & 1.000 & $.222^{*}$ & 1.000 \\
\hline OHRQoL-2 (P-CPQ) & $.206^{*}$ & .036 & $.229^{*}$ & 1.000 \\
\hline Social economy status & $.309^{* *}$ &. $.357^{* *}$ & -.056 & .031 \\
\hline Maternal age group & .000 & 1.000 \\
\hline
\end{tabular}

Spearman's correlation is significant at ${ }^{*} 0.05$ and ${ }^{* *} 0.01$ levels (two-tailed).

correlation result showed that 7 of 10 correlations were statistically significant, with $(r)$ values ranging between -0.36 and 0.31 .

\section{Model Testing (Outer Model) Result}

The formative measurement models, bootstrapping procedure results showed that the weight of all items was found to be significant $(t>1.96, P<0.05$ ), signifying that sufficient item, as an indicator, validity had been achieved. The items' weight ranged between 0.7 and 0.9. Furthermore, all variance inflation factor (VIF) values were found to be less than 3 , which means that there was no multicollinearity and indicating sufficient construct validity of the formative indicators (Table 4).

The reflective measurement model result revealed that this study's average variance extracted (AVE) range was on the recommended threshold (0.599). The heterotrait-monotrait ratio of correlation (HTMT) values was acceptable and ranged between 0.04 and 0.40 . All indicator loadings were above 0.70 , which is suitable for the recommendation. All reflective constructs revealed reliability values above the recommended level of 0.70 (Table 5). 
Table 4: Outer Weights, Statistical Significance, and Collinearity Assessment (VIF) of the Formative Constructs

\begin{tabular}{|c|c|c|c|c|c|}
\hline Construct & Item & Outer weights & t value & p-value & VIF \\
\hline \multirow{3}{*}{ Maternal oral health knowledge } & Tooth brushing practice & 0.894 & 13.164 & 0.000 & 2.334 \\
\hline & Dental treatment & 0.882 & 22.968 & 0.000 & 2.250 \\
\hline & Other oral care & 0.947 & 26.761 & 0.000 & 2.569 \\
\hline \multirow{2}{*}{ OHRQoL-1 } & Impact on child & 0.946 & 52.267 & 0.000 & 1.991 \\
\hline & Impact on the family & 0.897 & 22.606 & 0.000 & 1.991 \\
\hline \multirow{4}{*}{ OHRQoL-2 } & Child oral symptom & 0.883 & 5.982 & 0.000 & 2.267 \\
\hline & Child oral Function & 0.811 & 3.841 & 0.000 & 1.543 \\
\hline & Psychological wellbeing & 0.832 & 4.925 & 0.000 & 2.875 \\
\hline & Social wellbeing & 0.731 & 3.899 & 0.000 & 2.194 \\
\hline
\end{tabular}

Note: VIF: Variance inflation factor $<3$, t-value $>1.96, p<0.05$

Table 5: Reliability, Convergent and Discriminant Validity of Socioeconomic Status and Maternal Age Group Constructs

\begin{tabular}{|c|c|c|c|c|c|c|c|c|}
\hline \multirow{2}{*}{ Construct } & \multirow{2}{*}{ Item } & \multirow{2}{*}{$\begin{array}{l}\text { Reliability } \\
\text { Cronbach } \alpha\end{array}$} & \multicolumn{3}{|c|}{ Convergent validity } & \multirow{2}{*}{\multicolumn{3}{|c|}{ Discriminative Validity HTMT }} \\
\hline & & & Loadings & CR & AVE & & & \\
\hline \multirow{3}{*}{ Socio-economy status } & Education & \multirow{3}{*}{0.708} & 0.702 & \multirow{3}{*}{0.817} & \multirow{3}{*}{0.599} & \multirow{3}{*}{0.398} & \multirow{3}{*}{0.208} & \multirow{3}{*}{0.286} \\
\hline & Occupation & & 0.721 & & & & & \\
\hline & Wealth & & 0.7 .05 & & & & & \\
\hline Maternal age & Age group & 1.000 & 1.000 & 1.000 & 1.000 & 0.047 & & \\
\hline
\end{tabular}

Cut off values: Cronbach $\alpha>0.7$, Loading $>0.7, \mathrm{CR}>0.7$, AVE $>0.5, \mathrm{HTMT}<0.85$.

\section{Structural Model (Inner Model) Results}

Figure 2 summarizes the structural model results, including path coefficient $(\beta)$ and explained variance $\left(R^{2}\right)$. The $R^{2}$ value of OHRQoL-1 was 0.167 , indicating that only $16.7 \%$ of the variance in OHRQoL is predicted by maternal oral health knowledge, SES, and maternal age group, slightly higher than the $R^{2}$ value of OHRQoL-2 which was 0.083 (unacceptable level). A $10.6 \%$ of the variance (weak) in maternal oral health knowledge is predicted by SES and maternal age group. Results of individual testing of direct and indirect paths are presented in Tables 6 and 7, respectively.

\section{DISCUSSION}

This study confirmed the hypothesis that mothers with higher oral health knowledge had more significant effects on their stunting children's OHRQoL measured by ECOHIS, not by the P-CPQ. In addition, this study also confirmed the same way as the maternal age group; the higher the level of the maternal age group, the more significant effects on their stunting children OHRQoL measured by ECOHIS.
The concept of quality of life has been used widely for the assessment of health-related data. It defines the

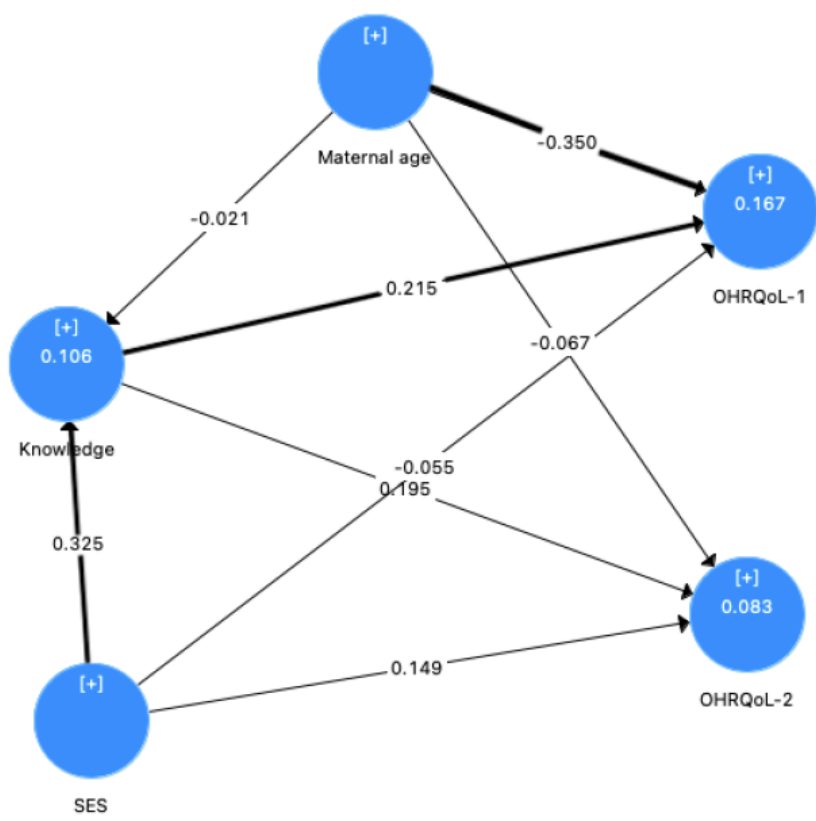

Figure 2: Structural model results. The number on the arrow $(\beta)$, the path coefficients; numbers inside the circle $\left(R^{2}\right)$, the explained variance; the arrow's thickness indicates the path coefficients weight to rank their relative statistical importance. 
Table 6: Path Coefficient and Significance of Research Hypotheses (Direct Effect)

\begin{tabular}{|c|c|c|c|c|c|}
\hline Hypothesis & Relationship & b & t-value & p-value & Decision \\
\hline $\mathrm{H} 1$ & OHK $\rightarrow$ OHRQoL-1 & 0.215 & 2.246 & 0.025 & Supported \\
\hline $\mathrm{H} 2$ & OHK $\rightarrow$ OHRQoL-2 & 0.195 & 1.094 & 0.275 & Unsupported \\
\hline $\mathrm{H} 3$ & SES $\rightarrow$ OHRQoL-1 & -0.055 & 0.402 & 0.688 & Unsupported \\
\hline $\mathrm{H} 4$ & SES $\rightarrow$ OHRQoL-2 & 0.149 & 1.033 & 0.302 & Unsupported \\
\hline $\mathrm{H} 5$ & $\mathrm{SES} \rightarrow \mathrm{OHK}$ & 0.325 & 2.854 & 0.004 & Supported \\
\hline $\mathrm{H} 6$ & MAG $\rightarrow$ OHRQoL-1 & -0.350 & 3.697 & 0.000 & Supported \\
\hline $\mathrm{H} 7$ & MAG $\rightarrow$ OHRQoL-2 & -0.067 & 0.546 & 0.585 & Unsupported \\
\hline $\mathrm{H} 8$ & $\mathrm{MAG} \rightarrow \mathrm{OHK}$ & -0.021 & 0.221 & 0.825 & Unsupported \\
\hline
\end{tabular}

$\mathrm{OHK}=$ oral health knowledge, SES=social economic status, $\mathrm{MAG}=$ maternal age group.

$\mathrm{t}>1.96$ at $p<0.05$.

Table 7: The Bootstrapping Analysis of Indirect Effect (Mediating Effect)

\begin{tabular}{|c|c|c|c|c|c|c|c|}
\hline Path & $\beta$ & $t$-value & $\mathbf{p}$-value & IV $\rightarrow$ mediator & Mediator $\rightarrow$ DV & $\begin{array}{c}\text { SD } \\
\text { LL-UL }\end{array}$ \\
\hline \hline MAG $\rightarrow$ OHK & -0.05 & 0.206 & 0.837 & - & - & 0.022 & -0.0520 .041 \\
\hline SES $\rightarrow$ OHK & 0.070 & 1.757 & 0.080 & - & - & 0.038 & -0.0010 .154 \\
\hline MAG $\rightarrow$ OHRQOL-1 & -0.004 & 0.177 & 0.860 & - & - & 0.023 & -0.0590 .043 \\
\hline SES $\rightarrow$ OHK & 0.064 & 0.969 & 0.333 & - & - & 0.066 & -0.0940 .169 \\
\hline
\end{tabular}

$\mathrm{OHK}=$ oral health knowledge, SES=social economic status, $\mathrm{MAG}=$ maternal age group.

$t>1.96$ at $p<0.05$.

individual's perception of his/her condition in life in terms of his/her aims, expectations, and standards within the culture and value system in which he/she lives. However, these assessments are modified in terms of children because their self-reporting should not be considered standard value to measure perceived OHRQoL. In these circumstances, parents are obligated to be assessed their perception of their children's OHRQoL [16]. It was found that those persons belonging to higher age groups tend to perceive their own or their family health in a significantly more positive fashion than members of younger adult age groups $[17,18]$. This study is the first that specifically examined the relationship between the maternal age group with the OHRQoL of their children.

The social-economic status of the family, which includes parents' educational background, occupation, and income, have both direct effects on maternal oral health knowledge. Zhang, in 2016, hypothesized the pathways from socioeconomic status and the modifiable factors, including oral health knowledge $[19,20]$. Explaining the possible indirect mechanism that links social-economic status to oral health knowledge is beyond the scope of this study. Nevertheless, one of the possible pathways through which the SES might affect maternal oral health knowledge is the maternal education level, which was a small part of the SES indicator. This assumption is supported by studies linking a different kind of education level with specific knowledge [21]. Education is every effort, influence, protection, and assistance given to children aimed at maturity. Mother's education through other related mechanisms such as productivity and the efficiency of health care indirectly affects the growth and development of children [22]. The education level of the research subjects in Table $\mathbf{1}$ is the most in the middle category (high school). The results of this study are similar to the research in Bojonegoro; namely, the incidence of stunting children is more common in mothers with a high school education level (60\%) [23].

In the structural model, the relationship between socioeconomic status and OHRQoL was not supported. This result contradicts the results of several studies $[24,25]$. The inconclusive findings are partially due to the type of SES measures used in this study. This study focused mainly on the observable measurements of SES, or so-called objective SES, thus neglecting the subjective SES, defined as an individual's perception of where he/she resides on the 
social ladder [26]. Objective SES was indexed by parental monthly income that was self-reported in the questionnaire. Self-reported data potentially suffer biases that most survey-based data do, including response bias and inaccurate reporting.

The Early Childhood Oral Health Impact Scale (ECOHIS) is an instrument to obtain OHRQoL in children aged 0-5 years and their families. Another instrument we used to measure OHRQoL in this study was the PCP-Q. We used two scales to compare which model fits the most. Path coefficient between oral health knowledge and maternal age group and OHRQoL was the strongest measured with ECOHIS ( $\beta$ $=0.215$ on oral health knowledge and $\beta=0.196$ on maternal age group).

The current model showed that maternal oral health knowledge contributes to OHRQoL of stunting children as both reflect the individual's perception of oral health. This finding confirms what has been recommended to use the global oral health rating concurrently with OHRQoL measures to assess better the broader meaning and significance of the functional and psychosocial impacts.

The included variables explained $17.2 \%$ of the variance in $\mathrm{OHRQ}$ L, which is considered moderate according to the cut-off points set by Cohen [27]. Maternal oral health knowledge was the most significant predictor that contributed an enormous amount to the model. This finding reflects their potential role in explaining OHRQoL, specifically to mothers of children with growth and development disturbance.

The predictive power of the OHRQoL construct was $\left(Q^{2}=10.7 \%\right)$, which indicates values that represent an evaluation criterion for the cross-validated predictive relevance of the model out of sample $[27,28]$. This result refers to the adequate ability of the current model to predict out of the sample, which further adds to the current model validity

\section{LIMITATIONS AND SUGGESTIONS FOR FURTHER RESEARCH}

We have limitations in this study; thus, the findings should be interpreted within these limitations. First, the data collection design (cross-sectional) used in this research is less rigorous than longitudinal studies. Therefore, it should be followed by further study to explore and confirm the findings with a longitudinal design.
Second, this study used a set of self-reported instruments that might be subject to social desirability or random responses, especially to social economy items. The participants were guaranteed confidentiality to minimize the effect of bias. They also were informed that these instruments are not a test, with no correct or preferred answer.

Third, the sample size that only covers one village invite a question of whether or not represent the 15 stunting locus village. Finally, the pandemic makes it difficult for researchers to reach all stunting loci in one period so that although these results are generally limited, they provide a guideline for further research that covers all stunting loci in the city of Bandung.

\section{CONCLUSION}

The relationship between oral health and the nutritional state of a child has been widely studied, but the results of this study conclude that other elements influence each other. Our findings show that maternal oral health knowledge had a more significant impact on OHRQoL if supported with maternal age group and social-economic status.

\section{AUTHOR'S CONTRIBUTIONS}

All people who meet authorship criteria are listed as authors, and all authors certify that they have participated in all the parts of the realization of the manuscript. A.S.S. conceived the ideas. A.S.S., R.I., T.R.N, and A.S collected and analysed the data. A.S.S., T.R.N, A.S, E.C contributed to drafting the manuscript. A.S.S. finalized the writing of the manuscript.

\section{FUNDING}

This study was funded by Universitas Padjadjaran Academic Leadership Grant for the fiscal year 2020 as a funding source.

\section{CONFLICT OF INTEREST}

None declared.

\section{ACKNOWLEDGEMENTS}

The authors wish to thank Universitas Padjadjaran for the Academic Leadership Grant.

\section{REFERENCE}

[1] Pritasari K. Arah kebijakan dan rencana aksi program kesehatan masyarakat tahun 2020 - 2024. Rapat Kerja Nas Kementeri Kesehat RI 2020; 1-31. 
[2] Kementerian Kesehatan RI. Laporan Pelaksanaan Integrasi Susenas Maret 2019 dan SSGBI Tahun 2019.

[3] Abdat M. Stunting Pada Balita Dipengaruhi Kesehatan Gigi Geliginya. J Syiah Kuala Dent Soc 2019; 4(2): 36-40.

[4] Sadida ZJ, Indriyanti R, Setiawan AS. Does Growth Stunting Correlate with Oral Health in Children?: A Systematic Review. Eur J Dent 2021; October: 1-7. https://doi.org/10.1055/s-0041-1731887

[5] Folayan MO, El Tantawi M, Schroth RJ, Vukovic A, Kemoli A, Gaffar B, et al. Associations between early childhood caries, malnutrition and anemia: A global perspective. BMC Nutr 2020; 6(16): 8

https://doi.org/10.1186/s40795-020-00340-z

[6] Bennadi D. Oral Health Related Quality Of Life. J Int Soc Prev Community Dent 2013; 03(1): 1-6. https://doi.org/10.4103/2231-0762.115700

[7] Agustian Y, Rusmil K, Solek P. Hubungan faktor sosioekonomi dengan perawakan pendek anak usia 24-60 bulan. Sari Pediatr 2018; 20(2): 106-14 https://doi.org/10.14238/sp20.2.2018.106-14

[8] Benghasheer $H$, Saub R. Relationships of acculturative stress, perceived stress, and social support with oral healthrelated quality of life among international students in Malaysia: A structural equation modelling. J Int Soc Prev Community Dent 2020; 10(4): 520-30.

https://doi.org/10.4103/jispcd.JISPCD_192_20

[9] Bhat SG, Sivaram R. Psychometric properties of the Malayalam version of ECOHIS. J Indian Soc Pedod Prev Dent 2015; 33(3).

https://doi.org/10.4103/0970-4388.160398

[10] Alzoubi EE. Oral Health Related Quality of Life Impact in Dentistry. J Dent Heal Oral Disord Ther 2017; 6(6): 35-42. https://doi.org/10.15406/jdhodt.2017.06.00221

[11] Buldur B, Güvendi ON. Conceptual modelling of the factors affecting oral health-related quality of life in children: A path analysis. Int J Paediatr Dent 2020; 30(2). https://doi.org/10.1111/ipd.12583

[12] Hakim L. Urgensi revisi undang-undang tentang kesejahteraan lanjut usia. Aspir J Masal Sos 2020; 11(1): 4355.

https://doi.org/10.46807/aspirasi.v11i1.1589

[13] Ghufroni ASA, Saptarini R, Chemiawan E. Gambaran Pengetahuan Dan Sikap Ibu Mengenai Pemeliharaan Kesehatan Gigi Dan Mulut Anak Sindroma Down Di Kota Depok. Univ Padjadjaran 2019.

[14] Ho AD, Yu CC. Descriptive Statistics for Modern Test Score Distributions: Skewness, Kurtosis, Discreteness, and Ceiling Effects. Educ Psychol Meas 2015; 75(3): 365-88. https://doi.org/10.1177/0013164414548576

[15] Preacher KJ, Kelley K. Effect size measures for mediation models: Quantitative strategies for communicating indirect effects. Psychol Methods 2011; 16(2): 93-115.

https://doi.org/10.1037/a0022658

[16] Başgül ŞS, Üneri ÖŞ, Çakin-Memik N. Parents' perception of the quality of life of children with intellectual disabilities. Turk J Pediatr 2011; 53(5): 541-6.
[17] Messaraa C, Richard TJC, Walsh M, Doyle L, O'Connor C, Robertson $\mathrm{N}$, et al. Perceived age and perceived health among a Chinese cohort: Does it mean the same thing? Int $\mathrm{J}$ Cosmet Sci 2020; 42(5): 471-81.

https://doi.org/10.1111/ics.12647

[18] Mahat G, Bowen F. Parental knowledge about urban preschool children's oral health risk. Pediatr Nurs 2017; 43(1): 30-4.

[19] Zhang Y, Wong MCM, Lo ECM. Pathways of oral health knowledge, attitudes, practices, and status in married couples. Community Dent Oral Epidemiol 2016; 44(4): 400-7. https://doi.org/10.1111/cdoe.12228

[20] Zhang Y, Li KY, Lo ECM, Wong MCM. Structural equation model for parental influence on children's oral health practice and status. BMC Oral Health 2020; 20(1): 1-8. https://doi.org/10.1186/s12903-020-1048-2

[21] Gomes APM, Silva EG da, Gonçalves SHF, Huhtala MFRL, Martinho FC, Gonçalves SE de P, et al. Relationship between patient's education level and knowledge on oral health preventive measures. Int Dent Med J Adv Res - Vol 2015 2015; 1(1)

https://doi.org/10.15713/ins.idmjar.6

[22] Waqidil H. AC. Hubungan antara tingkat pendidikan ibu dengan perkembangan balita usia 3-5 tahun). Asuhan Kesehat 2016; 7(2): 27-31.

[23] Lailatul M, Ni'mah. C. Hubungan Tingkat Pendidikan, Tingkat Pengetahuan dan Pola Asuh lbu dengan Wasting dan Stunting pada Balita Keluarga Miskin. Media Gizi Indones 2015; 10(2015): 84-90.

[24] Knorst JK, Sfreddo CS, de F. Meira G, Zanatta FB, Vettore M V., Ardenghi TM. Socioeconomic status and oral healthrelated quality of life: A systematic review and meta-analysis. Community Dent Oral Epidemiol 2021; 49(2): 95-102. https://doi.org/10.1111/cdoe.12616

[25] Moghaddam LF, Vettore MV, Bayani A, Bayat AH, Ahounbar $\mathrm{E}$, Hemmat M, et al. The Association of Oral Health Status, demographic characteristics and socioeconomic determinants with Oral health-related quality of life among children: a systematic review and Meta-analysis. BMC Pediatr 2020; 20(1): 489.

https://doi.org/10.1186/s12887-020-02371-8

[26] Huang S, Hou J, Sun L, Dou D, Liu X, Zhang H. The effects of objective and subjective socioeconomic status on subjective wellbeing among rural-to-urban migrants in China: The moderating role of subjective social mobility. Front Psychol 2017; 8(MAY). https://doi.org/10.3389/fpsyg.2017.00819

[27] Cohen J. Statistical Power Analysis for the Behavioral Sciences. Statistical Power Analysis for the Behavioral Sciences 2013. https://doi.org/10.4324/9780203771587

[28] Hair JF, Ringle CM, Gudergan SP, Fischer A, Nitzl C Menictas C. Partial least squares structural equation modeling-based discrete choice modeling: an illustration in modeling retailer choice. Bus Res 2019; 12(1): 115-42. https://doi.org/10.1007/s40685-018-0072-4

https://doi.org/10.6000/1929-6029.2021.10.19

(c) 2021 Indriyanti et al.; Licensee Lifescience Global.

This is an open access article licensed under the terms of the Creative Commons Attribution License (http://creativecommons.org/licenses/by/4.0/) which permits unrestricted use, distribution and reproduction in any medium, provided the work is properly cited. 